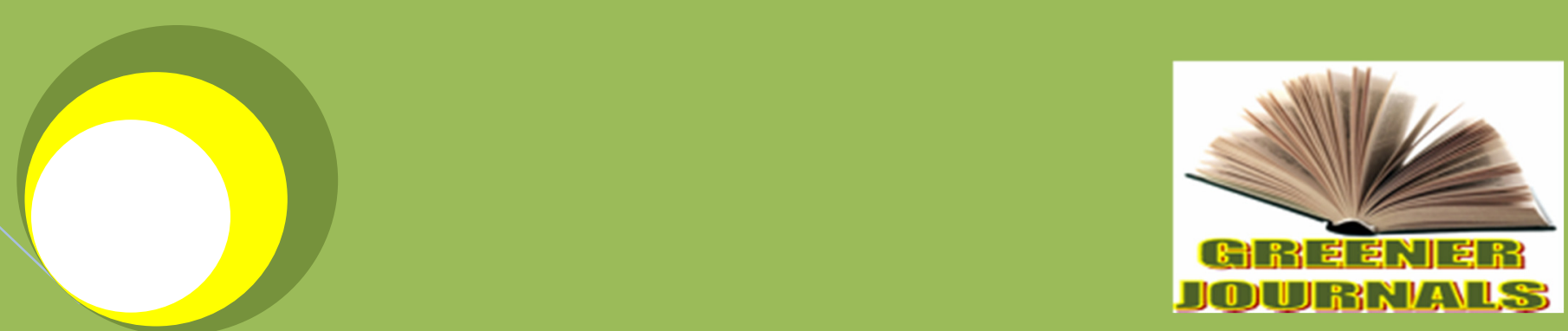

Greenert lournal of Medical Sciences ISSN: 2276-7797 ICV: 5.98

Submitted:14/03/016 Accepted: 22/03/2016

Published: 30/03/2016

DOI: http://doi.org/10.15580/GJMS.2016.1.031416061

Epi-Statistical Analysis of Early Years Mortality in Abu Dhabi, United Arab Emirates

By

Yeboah David Achanfuo 


\title{
Epi-Statistical Analysis of Early Years Mortality in Abu Dhabi, United Arab Emirates
}

\section{Yeboah David Achanfuo}

\author{
Professor of Epidemiology, College of Arts and Sciences, Abu Dhabi University, P O Box 59911, Abu Dhabi, UAE. \\ Email: david.yeboah @adu. ac.ae
}

\begin{abstract}
This study undertakes epi-statistical analysis of early years mortality data in Abu Dhabi, i.e. mortality for the first 4 years of life in Abu Dhabi. This methodology involves the computation of rates and related measures during the period 20102911. The study found clear disparities in mortality by geographical region in the Abu Dhabi population aged 0-4 years. The study found further that stillbirths, neonatal mortality and infant mortality declined in Abu Dhabi during the 2010-2011 period.The study concludes that the massive improvements in early years mortality is likely to continue as the Emirate embarks on further developments in the health sector. The study concludes further that health care affordability, resulting from mandatory health insurance, has improved access to and use of health services in maternity and obstetrics. It is also the contention of the study that the improvements will continue into the future.
\end{abstract}

Keywords: Early years, mortality, stillbirths, neonatal infant Abu Dhabi

\section{INTRODUCTION}

The Early years period is very important in the life of the child, and it is during this period that solid foundations are usually laid for the child's future health. Throughout the world, there is little published research on early years mortality, compared with general mortality and other measures of mortality, and the United Arab Emirates (UAE) and Abu Dhabi are no exceptions. Included in early years mortality are neonatal mortality, infant mortality and child mortality, albeit this study also examines stillbirths or fetal mortality at the end stage. Infant mortality is an important indicator of development today. Lower infant mortality is now associated with more developed societies while higher infant mortality is found in less developed societies.

The purpose of the current study is to investigate early years mortality in Abu Dhabi with a particular focus on establishing the levels and patterns of mortality and identifying the underlying reasons for the levels and patterns. Studies on these topics are conspicuously missing in the published research literature on the UAE and the Gulf Cooperation Council countries (popularly known as the GCC). This is the added significance and rationale behind this study.

\section{Data sources and methodology}

Data used in this study have come from the statistical resources of the Health Authority Abu Dhabi (HAAD), albeit some routine data have been obtained from other sources. The data include information on the population, stillbirths, neonatal mortality and child mortality for 2010 and 2011. The methodology involves an epi-statistical analysis of mortality data. This includes the computation of various indicators of mortality for the 0 to 4 years age group and a comparative analysis by geographical region. A comparison of early years mortality in 2010 and 2011 is also undertaken.

\section{LITERATURE REVIEW}

Not much exists on early years mortality and health care in particular and population and health generally, in the published research literature on the UAE. Raven (2002) discussed the intersection of healthcare organizational ethics, pointing out that healthcare providers are business organizations with ethical issues .Gulf News (2011) reported warnings from health professionals regarding the sale of prescription medication over the counter. 
National Newspaper (2011:1) pointed out the growing problems with waiting lists for various health procedures in the UAE while Yeboah (2007) examined population growth and the demand and provision of health services in the UAE up to 2006. He found that population growth was accompanied by new medical centers and increased number of public and private health services.

Okaida (2003) examined mental health in the Arab world while Zafar (2003) focused on women empowerment in the Arab world. Bener et al. (1993) investigated variables affecting health in the UAE, focusing on primary health care. They examined the 1986-1991 health strategy and concluded that health care had improved in the UAE. In addition, Matthew (2001) studied obesity in the UAE, indicating that there was a need to target obesity in the UAE. He concluded that obesity has a far greater impact in the UAE than acknowledged. UAE Ministry of Health (2001) presented professional code of conduct for health professionals, defining clearly what ethical practices were expected from medical practitioners and other health professionals. Ethical issues in health care have not received any attention in the published research literature on the UAE.

More recently. Yeboah (2014) investigated the over the counter sale of prescription only medicines in Abu Dhabi and found an endemic practice of selling and buying medicines over the counter without prescription as required by law.

\section{FINDINGS}

Early years population

The Emirate of Abu Dhabi comprises 3 Regions, namely Abu Dhabi (City), Al Ain (City and environs) and Western Region.

Table 1: Population by Region and Nationality, Abu Dhabi, 2011

\begin{tabular}{|l|l|l|l|l|l|}
\hline Region & Nationals & $\%$ of Total & Expatriates & $\%$ of Total & Total \\
\hline Abu Dhabi & 228,228 & $12.8 \%$ & $1,560,966$ & $87.2 \%$ & $1,789,194$ \\
\hline Al Ain & 177,117 & $36.5 \%$ & 307,590 & $63.6^{\wedge}$ & 484,707 \\
\hline Western & 28,440 & $19.2 \%$ & 120,059 & $80.8 \%$ & 148,499 \\
\hline Total & 433,785 & & $1,988,615$ & & $2,422,400$ \\
\hline
\end{tabular}

Source: HAAD, 2011

Of the total population of 2,422,400 living in Abu Dhabi in 2011, 160,829 (6.6\%) were in the early years age group, i.e. $0-4$ years old. As indicated in table 1 , the early years population consisted of 84,233 males $(52.4 \%)$ and 76,596 females (47.6\%). In addition, the 160,829 0-4 years population comprised 68,151 Nationals and 92,678 Expatriates. Therefore, about $57.6 \%$ of the Abu Dhabi population aged 0-4 years old were born to the Expatriate population.

Table 2: Population aged 0-4 years, Abu Dhabi, 2011

\begin{tabular}{|l|l|l|l|}
\hline P2pulation Subgroup & Males & Females & Total \\
\hline Nationals & 35.863 & 32.288 & 68.151 \\
\hline Expatriates & 48.370 & 44,308 & 92,678 \\
\hline Total & 84,233 & 76,596 & 160,829 \\
\hline
\end{tabular}

Source: Derived from HAAD 2011

\section{Livebirths}

Table 3shows total livebirths in Abu Dhabi by Nationals and Expatriates in 2010 and 2011. In 2010, Abu Dhabi recorded a total of 29,528 livebirths and this increased to 32,084 in 2011 , an increase of $8.7 \%$. $51 \%$ of the livebirths in 2011 were males compared to $49 \%$ females. The distribution of livebirths by Region is indicated in table 3 , with Abu Dhabi City accounting for over $60 \%$ of the births. 
Table 3: Total livebirths by Region, Abu Dhabi, 2011

\begin{tabular}{|l|l|l|}
\hline Region & Livebirths & \% of Total livebirths \\
\hline Abu Dhabi & 19,312 & 60.7 \\
\hline Al Ain (Eastern) & 11,397 & $35.8 \%$ \\
\hline Western & 1,089 & $3.4 \%$ \\
\hline \multicolumn{2}{|l}{ Source: Derived from HAAD, 2011 } \\
\hline
\end{tabular}

\section{Mortality}

Early years mortality is presented at 4 levels namely stillbirths, neonatal mortality, infant mortality and child mortality. In 2010, a total of 660 early years mortality was recorded for Abu Dhabi and this decreased to 475 in 2011, a decline of $28 \%$. Early years mortality constituted $22.9 \%$ of all deaths in Abu Dhabi in 2010 and tie corresponding proportion for 2011 was $16.4 \%$. Both the number and proportion of early years deaths declined between 2010 and 2011 (table 4).

Table 4: early years mortality in the Emirate of Abu Dhabi in 2010 and 2011 by type of mortality

\begin{tabular}{|l|l|l|l|}
\hline Deaths & $\mathbf{2 0 1 0}$ & $\mathbf{2 0 1 1}$ & \%change 2010-2011 \\
\hline Stillbirths & 182 & 68 & -123.6 \\
\hline Neonatal Mortality & 133 & 127 & -4.5 \\
\hline Infant Mortality & 235 & 205 & -12.8 \\
\hline Child Mortality & 60 & 75 & 25.0 \\
\hline Total & 660 & 475 & -28.0 \\
\hline
\end{tabular}

Source Derived from HAAD Databases

Table 5 shows early years mortality for Abu Dhabi Emirate by type and geographical region. As expected, Abu Dhabi City recorded the largest number and proportion for each category of death.

Table 5: Early years mortality by type and geographical region, 2011

\begin{tabular}{|l|l|l|l|l|l|l|}
\hline Deaths & $\begin{array}{l}\text { Abu Dhabi } \\
\text { City }\end{array}$ & $\%$ & $\begin{array}{l}\text { Eastern (Al } \\
\text { Ain) }\end{array}$ & $\%$ & Western & $\%$ \\
\hline Stillbirths & 57 & 83.8 & 8 & 11.8 & 3 & 4.4 \\
\hline $\begin{array}{l}\text { Neonatal } \\
\text { mortality }\end{array}$ & 102 & 80.3 & 21 & 16.5 & 4 & 3.1 \\
\hline Infant mortality & 157 & 77.7 & 40 & 19.8 & 5 & 2.5 \\
\hline Child mortality & 47 & 65.3 & 22 & 30.6 & 3 & 4.2 \\
\hline
\end{tabular}

\section{Stillbirths}

Stillbirths constituted $27.6 \%$ of all early years deaths in the Emirate of Abu Dhabi (Abu Dhabi City, Eastern and Western) in 2010 and this declined marginally to $26.7 \%$ in 2011. According to table 4, the number of stillbirths declined by $123.6 \%$ during the $2010-2011$ period. The geographical distribution shows that 57 or $83.8 \%$ of the stillbirths in 2011 occurred in Abu Dhabi City, 8 or $11.8 \%$ in Eastern Region (Al Ain) and 3 or $4.4 \%$ in the Western Region (table 5).

\section{Neonatal mortality}

It can be derived from table 4 that neonatal mortality constituted $20 \%$ of all early years deaths in the Emirate of Abu Dhabi in 2010and this increased to $26.7 \%$ in 2011. Table 4 shows that the number of neonatal death recorded only a very small decline of 6 during 2010 and 2011. The geographical distribution shows that 102 or $80.3 \%$ of the stillbirths in 2011 occurred in Abu Dhabi City, 21 or 16.5\% in Eastern Region (Al Ain) and 4or 3.1\% in the Western Region (table 5). 


\section{Infant mortality}

According to table 4, infant mortality declined from 235 in 2010 to 205 in 2011 , a decline of $12.8 \%$. In addition, infant mortality accounted for 157 deaths, a $3^{\text {rd }}$ of all deaths of early years in the Emirate of Abu Dhabi in 2011. It is discernable from table 4 that infant mortality constituted $35.6 \%$ of all deaths in 2010 and $43.2 \%$ of all early years deaths in the Emirate of Abu Dhabi. In terms of geographical distribution, 157or 77.7\% of the infant deaths in 2011 occurred in Abu Dhabi City, 8 or $11.8 \%$ in Eastern Region (Al Ain) and 3 or $4.4 \%$ in the Western Region (table 5).

\section{Child mortality}

It can further be derived from table 4 that child mortality constituted only a small proportion of early years mortality, $9.1 \%$ in 2010 and $15.8 \%$ in 2011 . According to table 4, the number of child deaths declined by $25 \%$ during the $2010-$ 2011 period. The geographical distribution shows that 47 or $65.3 \%$ of the child deaths in 2011 occurred in Abu Dhabi City, 22 or $30.6 \%$ in Eastern Region (Al Ain) and 3 or $4.2 \%$ in the Western Region (table 5).

\section{DISCUSSION}

Mortality is a key area in the study of health and the early years population constitutes an integral component of the population of any society. The population of Abu Dhabi has been increasing steadily and the early years population has contributed to this growth. In 2011, Abu Dhabi Emirate recorded a total population of 2,422,300. Of this population 160,829 were aged 0-4 years (6.6\%). It is notable to mention that the geographical distribution of livebirths and the total population is skewed towards the City of Abu Dhabi and this is consistent with the status of Abu Dhabi as the Capital of the Emirate and the Nation.

There has been a sharp decline in the level of early years mortality in the Emirate of Abu Dhabi. From 2010 to 2011 , early years mortality dropped from 600 to 475 , a decline of almost $23 \%$. This decline occurred alongside a decline in maternal mortality. In fact maternal mortality has been halved in the United Arab Emirates (Rizvi and Bell, 2016), and it is, therefore, not surprising that early years mortality has also declined. The largest decline occurred in the number of stillbirths (-123.6\%). Only child mortality increased during 2010 to 2011 and this is due to improved medical records arrangements including data collection and storage. With the vast improvement in levels of immunization (95\% of all new born babies), child mortality is expected to decline in the near future.

These declines in early years mortality are consistent with what is happening in the country as a whole. According to Rizvi and Bell (2016), Infant mortality rate in the UAE dropped from 14 per 1000 livebirths in 1990 to just 7 per 1000 livebirths in 2013 , a decline of $50 \%$ for the country. They reported further that child mortality also halved during the same period.

The improvements in early years mortality is largely due to advances in health and medical practices and health care provision in Abu Dhabi in particular and the UAE in general. There has been massive improvements in the provision of health care to meet increasing demand which has been caused by rapid population growth (Yeboah, 2007; Rosling, 1999).As noted by Manchat (2016), health care is a priority sector for the Government of the UAE and that has resulted in a steady growth of the sector in recent years. A number of programs have been developed and delivered to relevant groups including women, infants and children under 5 years old. These programs include immunization, antenatal and postnatal care for pregnant women and general health education. There are various hospitals specializing in maternity and obstetrics in Abu Dhabi and around the country. Together, these advances have resulted in massive improvements in maternal and child health in Abu Dhabi.

Another contributing factor is the affordability of health care (Manchat, 2016). The introduction of mandatory health insurance in Abu Dhabi Emirate has increased the affordability of health care. Pregnant women can now easily access the health care they need, resulting in healthy gestation and childbirth. In addition, health care is free for all UAE nationals who also enjoy free overseas trips to access health care if required. The improvements in early years mortality is set to continue unabated. Health Authority Abu Dhabi (HAAD) has announced major projects in health care including 2000 hospital beds for various medical conditions including maternity and obstetrics (Gulf News, 2016)

\section{CONCLUSION}

This study investigates early years mortality in the Emirate of Abu Dhabi, and establishes that early years mortality has improved dramatically in the Emirate. It also identifies various reasons which underpin the improvements. The study concludes that the massive improvements in early years mortality is likely to continue as the Emirate embarks 
on further developments in the health sector. The study concludes further that health care affordability, resulting from mandatory health insurance, has improved access to and use of health services in maternity and obstetrics. This has resulted in decline in early years mortality. It is also the contention of the study that the improvements will continue into the future.

\section{REFERENCES}

Bener A, Abdulla Sand, Murdoch J C (1993): Primary Health Care in the United Arab Emirates.Family Practice, Vol 10, Issue 4:440-448.

Gulf News (2011): Overdosing is a common problem. October 9 issue.

Gulf News (2016): Abu Dhabi outlines health care targets. January 25 issue, page A9.

Manchat, P (2016): The future of UAE health care sector will be lively. Arabian business, Vol. 17, Issue 5: 20-21.

Matthew A P (2001): Obesity: A big problem in the UAE. UAE University.

National Newspaper (2011): Hospital blames waits on system. October 7 issue, p 2.

Okaida A (2003): Mental health service in the Arab World. Arab Studies Quarterly, Vol 25, No 4:39-52.

Raven C (2002): The intersection of healthcare organizational ethics. Abu Dhabi, Ethics Resource Center.

Rizi, A and Bell J (2015): UAE rate of death in childbirth has halved. The National, 25 May issue, 1-6.

Rosling H (1999): Health development in the UAE from a global perspective. Abu Dhabi, Emirates Centre for Strategic and Scientific Research.

UAE Ministry of Health (2001): Professional code of conduct for primary health care staff. Abu Dhabi, Ministry of Health.

Yeboah D A (2007): The impact of population variables on health services demand and provision in the UAE. Arab Studies Quarterly, Vol 29, No 1: 61-78.

Yeboah, D A (2014): Over the counter sale of prescription medicines in Abu Dhabi.British Journal of Applied Science and Technology, Vol. 4, No. 17: 1128-1137.

Zuhur S (2003): Women development in the Arab World. Arab Studies Quarterly, Vol 25, No 4: 17-38.

Cite this Article: Yeboah David Achanfuo (2016). Epi-Statistical Analysis of Early Years Mortality in Abu Dhabi, United Arab Emirates. Greener Journal of Medical Sciences, 6(1) 025-029, http://doi.org/10.15580/GJMS.2016.1.031416061 